\title{
Human milk and neurodevelopment in children with very low birth weight: a systematic review
}

\author{
Winston Koo ${ }^{{ }^{*}}$, Surinder Tank ${ }^{1}$, Sandra Martin ${ }^{2}$ and Runhua Shi ${ }^{3}$
}

\begin{abstract}
Human milk (HM) contains critical nutrients and possibly other neurotrophic factors that could benefit the less developed brain of preterm infants, particularly those with very low birth weight (VLBW). This study aims to systematically review the original studies to determine whether there is a reproducible independent effect of HM feeding on neurodevelopment outcome in preterm VLBW infants. Search of seven databases (PubMed, Cochrane, CINAHL, Embase, Proquest Research Library, Google Scholar, and Web of Science) identified 24 original studies. Each study was evaluated by two authors independently for 8 non-nutritive (study design, target population, a priori power calculation, adjustment for baseline growth status, postnatal complication, other confounders, observer blinding to feeding status, effect size) and 5 nutritive (definition and duration of HM intake, use of HM fortifier, source of HM data, infant formula used) methodology parameters, and consistency and directness of outcome measures. Thirteen reports of preterm infants with wide ranges of birth weights were excluded as none provided sufficient data to delineate the effects of HM feeding on developmental outcome of subjects with VLBW. Eleven reports included only VLBW children and 7 studies were reviewed after elimination of preliminary data from same cohort or lack of appropriate standardized testing or control group. These 7 studies ( $n=18$ to 704, median 219) were performed at $<3$ years (3 studies) and at 5 to 11 years ( 4 studies). Six studies were secondary analysis of data from other studies. Each study met or only partially met 4 to 10 methodological parameters. VLBW children with no neurological impairment fed HM achieved normal or low normal range of test scores. Formula feeding using older formulations was associated with a lower subtest score in 4 studies. There is no randomized clinical trial comparing the neurodevelopment outcome of HM versus formula or minimal HM feeding that included only children with VLBW. The role of HM in the neurodevelopment and cognitive function of VLBW children needs reassessment with high quality studies in the context of current formulations of HM fortifier and preterm formula.
\end{abstract}

Keywords: Preterm, Very low birth weight, Milk, Human, Breast milk, Donor milk, Neurodevelopment or cognitive function

\section{Introduction}

Preterm very low birth weight (VLBW, $<1,500 \mathrm{~g}$ ) infants are at high risk for growth failure and co-morbidities that result in delayed neurodevelopment and academic achievement [1-3]. Early nutrition support is recognized as critical to growth and development and exclusive breastfeeding is universally recommended as beneficial to the health and well-being for all infants [4-6]. However, human milk (HM) alone does not support optimal growth for VLBW infants, so multinutrient fortification,

\footnotetext{
* Correspondence: wkoo@lsuhsc.edu

'Department of Pediatrics, Louisiana State University Health Sciences, 1501 Kings Hwy, Shreveport, LA, USA

Full list of author information is available at the end of the article
}

focusing on protein, minerals, vitamins and other nutrients is recommended [4-6]. Preterm VLBW infants are born at a period of significant phase of in utero organ development and are at risk for deficiency of essential nutrients and trophic factors critical to the growth and function of the nervous system. The less developed brain of preterm infants, particularly those with VLBW, theoretically could benefit from feeding maternal milk since it contains critical nutrients such as long chain polyunsaturated fatty acids (LCPUFA) and possibly other neurotrophic factors. This is supported by a review of earlier studies which indicated that HM has greater neurodevelopment benefits than formula for feeding preterm infants [7]. 
Significant methodological issues arise in the determination of the effect of feeding HM on neurodevelopment outcome. Since it is neither feasible nor ethical to assign breastfeeding randomly, determining the effect of breastfeeding is invariably based on observation. This has challenges particularly in controlling for factors to minimize the risk of bias [8-10]. One quasi-randomized trial in preterm infants of varying birth weights and gestational ages showed significant neurodevelopment benefit for infants fed HM [11]. This and other reports [7], did not adequately control for perinatal and postnatal complications, social and environmental factors that can affect neurodevelopment, and had limited data on the role of HM feeding on neurodevelopment of the group at greatest risk for neurodevelopment impairment, namely children with VLBW. The aim of this study is to systematically review the original studies to determine whether there is a reproducible independent effect of HM feeding on neurodevelopment outcome in preterm VLBW infants.

\section{Methods}

\section{Identification of articles}

A systematic search of the literature was conducted for studies published in English that examined the effect on neurodevelopment and cognitive outcomes from breast milk feeding to VLBW infants. Literature searches of the databases Medline (via PubMed) from 1988, Cochrane Library from 1982, Cumulative Index to Nursing and Allied Health Literature (CINAHL) from 1992, Embase from 1988, Proquest Research Library from1990, Google Scholar from 1994, and Web of Science from 1992 were performed on several occasions with a final search performed on August 11, 2014.

The PubMed search strategy employed a 5 step process using medical subject headings ( $\mathrm{mh}$ ) and related subject/ keyword/text word (tw) terms. The first 4 searches were performed independently followed by the 5 th search which combined the results from first 4 searches within each database to obtain the articles to be screened for relevance and subsequent review. The first search include infant, premature (mh), OR infant, very low birth weight (mh) OR Very low birth weight (tw) OR extremely low birth weight (tw) OR preterm infants (tw). The second search include breast feeding (mh) OR milk, human (mh) OR breast milk (tw) OR donor milk (tw) OR donor human milk (tw) OR maternal milk (tw). The third search include child development (mh) OR cognition (mh) OR intelligence (mh) OR neurodevelopment (tw) OR cognitive development (tw) OR brain development (tw) OR cognitive outcomes (tw) OR development cognitive (tw). The fourth search include outcome (all fields) OR effect (all fields). The fifth search combined the results from first 4 searches. This procedure was followed for all databases except for some variation in the search terms specific to a database.
For the purpose of this review, "human milk" was defined as breast milk from the mother (own mother's milk, OMM) or one or more donors (donor milk, DM), whether it was delivered by gavage or a nipple from the bottle or breast. "Neurodevelopment outcome" was defined as the attainment of age-appropriate developmental milestones or specific testing of intelligence or educational achievement. Study outcome limited to behavior/temperament tests or motor ability alone were not considered since their value as the sole predictor of long term neurodevelopment or cognitive function is not well established.

Titles and available abstracts of all studies compiled from the final electronic database search were screened by the investigators to determine eligible studies. Peer reviewed original studies independently assessed the relationship between HM and neurodevelopment outcome were identified. Reports of VLBW children studied as part of a larger cohort of preterm children with greater range of birth weights were included if the data clearly delineated to allow assessment of neurodevelopment effect on VLBW children from HM feeding. Bibliographies from these articles were also searched for additional applicable studies. For each cohort with multiple publications, only the publication with the longest duration of neurodevelopment follow-up was included in this review.

\section{Evaluation of articles}

We evaluated each article following the principles of systematic review [12] and similar to previous reports [8-10,13] but with modifications pertinent to the VLBW situation. To minimize bias of this systematic review, each study was evaluated independently by two authors (WK and ST) according to a list generated a priori, and the final result was a consensus reached by both authors.

To minimize bias within each study and across studies, each study was reviewed according to a list of nonnutritive and nutritive parameters. The non-nutritive parameters included 1) study design and whether the study's primary goal was the determination of the effect of breast milk on neurodevelopment or a secondary analysis in a non-breast milk related project, 2) target population, whether VLBW infants were included as part of the preterm population with higher birth weights or were the sole target, 3) predetermined sample size for different feeding groups, 4) whether adjustments were made for baseline differences in other variables such as the presence of intrauterine growth retardation (IUGR), 5) documentation of the extent of postnatal complications that could compromise the neurodevelopment outcome including the extent of intracranial hemorrhage, chronic lung disease, necrotizing enterocolitis, retinopathy of prematurity, severe neurosensory impairment, documented sepsis; how this information was managed 
and whether infants with serious complications were excluded from the data analysis, 6) control for bias in neurodevelopment and cognitive outcome, namely whether studies were controlled for socioeconomic status, maternal intelligence, and child rearing environment using Child Life Experience [14], Home Observation for Measurement of the Environment [15] or similar assessment tool, 7) whether observers of the outcome were blind to feeding status, 8) whether the study reported an effect size or some other strategy to interpret the clinical impact of the results. Nutritive parameters on the availability of feeding data included 1) definition and 2) duration of HM intake, 3) the type and amount of fortification, 4) source of HM feeding data, and the 5) type of non-HM feeding support. To accommodate the varied ages and circumstances of included children, all data from standardized tests of neurodevelopment or general intelligence were included. All quantitative and statistical data presented were based on each publication without any assumption or modification.

We also assessed the quality of each study [16] according to study design, whether the methodological criteria were met, and consistency and directness of outcome measures.

\section{Results}

Figure 1 indicates the number of articles screened and the final number of studies reviewed. A total of 24 reports of original studies that included HM feeding and neurodevelopment outcome in VLBW children were identified. Thirteen reports were excluded as none of these publications provided sufficient data to delineate the effects of HM feeding on developmental outcome of subjects with VLBW [11,17-28]. Of these $13 \mathrm{pu}-$ blications, six [11,22-26] were reports of selected subsets ( $\mathrm{n}=50$ to 438 ) from the same original study populations of 926 subjects. The average birth weights were $\sim 1400 \mathrm{~g}$ and 26 to $38 \%$ of the subjects were small for gestation (SGA). Two population-based cohorts $[17,28]$ from the same country included $>1400$ preterm infants in each cohort. The mean (SD) birth weights of HM fed groups were 1430 (SD 280) g and 1460 (SD 400) g respectively. The birth weights were significantly higher (average $100 \mathrm{~g}$ ) and as was the mean gestation (average $\sim 0.5$ week) than non HM groups. Five other publications [18-21,27] reported neurodevelopment of subjects with birth weights up to $2000 \mathrm{~g}$ $(\mathrm{n}=39$ to 388$)$. Two of these publications $[19,21]$ reported on the same cohort.

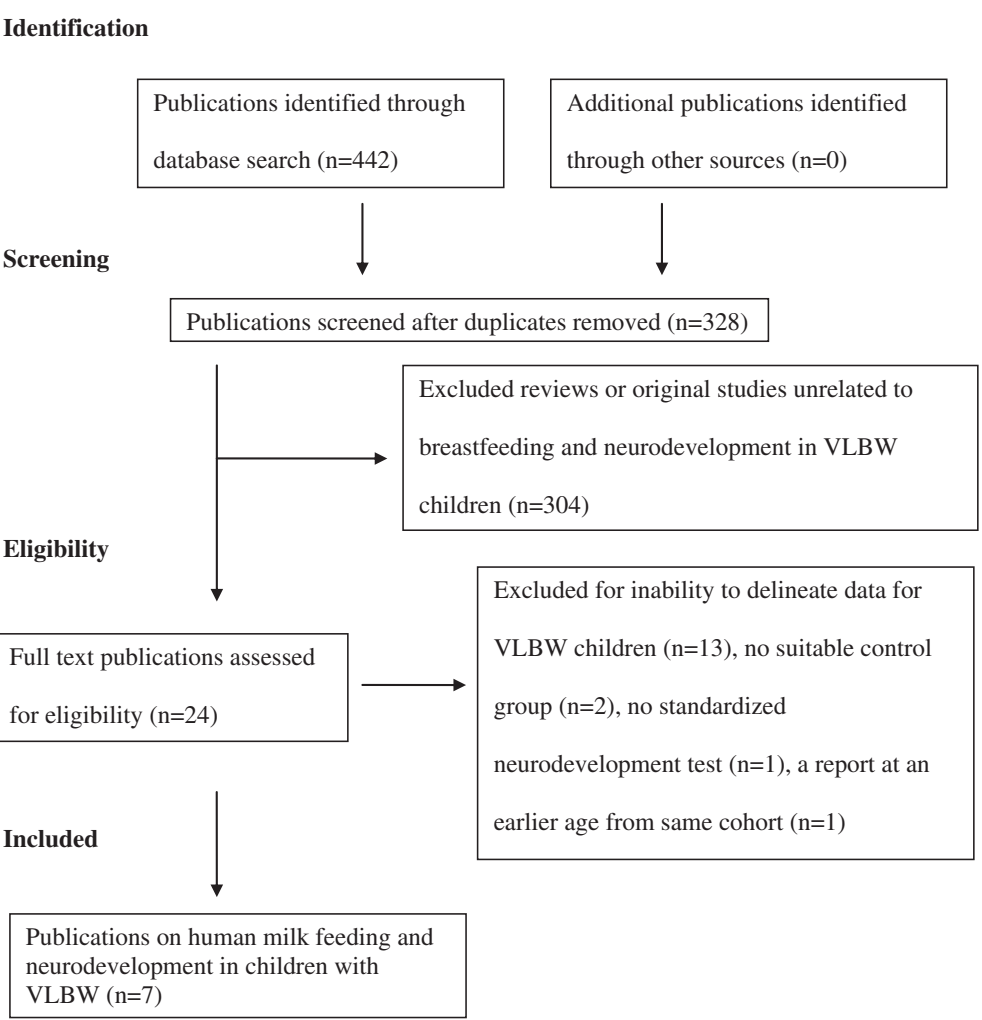

Figure 1 Search strategy to obtain original studies assessing the effect of feeding human milk on neurodevelopment of children with very low birth weight. 
Eleven reports included only VLBW children [29-39]. Four of these publications were excluded because there was another publication of the same cohort at a younger age [36], no formal standardized neurodevelopment tests were performed [37] and no suitable control group was defined as the study involved supplementation of docosahexaenoic acid and arachidonic acid of HM fed infants $[38,39]$. Of the remaining 7 studies of VLBW children, 2 included only children with birth weights $<1000 \mathrm{~g}[34,35]$.

Table 1 shows clinical characteristics of 7 studies of developmental outcome associated with HM feeding in VLBW infants. Three studies [30-32] reported the number of SGA infants with birth weight of $<10$ th percentile as surrogate for IUGR. SGA was reported to be as high as $62 \%$ in one study [31]. The numbers of children from multiple births also were not well documented.

Table 2 shows details of non-nutritive methodological parameters. All were observational studies dependent on maternal choice whether to provide breast milk with varying amount of OMM provided to their VLBW infant. In 6 of 7 studies, the effects of HM feeding on neurodevelopment were extracted via secondary analysis of data from other projects. The design of the primary studies was epidemiologic observational with 2 interventional studies: one on structured counseling to promote breastfeeding [29] and the other on glutamine supplementation in parenteral nutrition [35]. Three studies $[31,33,35]$ included only subsets of the study population from primary study. Exclusion criteria were generally clearly defined although varied among different studies. Three studies $[29,30,35]$ included children assessed at younger than 3 years and 4 studies included children from 5 to 11 years [31-34]. Sample sizes varied from 18 to 704 (median 219) children and none stated a priori power calculation to measure the effect of breast milk. The attrition rate of the subjects assessed tends to increase with increased duration of follow-up. Blinding of the observers to the feeding status of the subjects was reported in 3 studies [29,30,34].

In all studies, VLBW children without neurological impairment fed HM achieved normal or low normal scores on standardized tests of neurodevelopment or cognitive function. Thus any advantage of HM feeding is due to the lower scores of formula-fed infants. Two studies [29,31] used dichotomous grouping with $80 \%$ of the intake of HM as a cutoff point. For the group that received the most $\mathrm{HM}$, one of these two studies reported a higher raw score in one subtest of neurodevelopment at 5 years of age but no adjustments were made to account for confounders [31]. The other study showed no significant difference in adjusted scores [29]. One study at 30 months corrected age showed HM feeding during the hospitalization resulted in mean Mental Developmental Index (MDI) and Psychomotor Developmental Index (PDI) scores on the
Bayley Scales of Infant Development (BSID) in the low normal range; those fed infant formula have significantly lower scores [35]. Two of the 3 studies with neurodevelopment assessment at 6 to 11 years showed that HM feeding at highest volume was associated with intelligence test scores in the normal range. The formula fed group showed a significantly lower score in verbal intelligence quotient (IQ) in one study [32] and in visual motor skill subtest in another study [33]. The third study [34] reported that children born extremely preterm without major neurological impairment showed significantly poorer academic attainment on reading and mathematics than their term peers; HM feeding positively affected reading, but not mathematics attainment, at 11 years. In the same study, breast milk consumption together with perinatal and neonatal complications and socio-economic status accounted for $29 \%$ of the variance in reading attainment at 11 years.

Table 3 shows every study obtained some data on perinatal, postnatal, social and environmental factors. However, the extent of the details varied greatly. The statistical handling of the numerous variables also varied among studies and only one study adjusted for the SGA status.

Table 4 shows the nutritive parameters assessed in each study. Details on the extent and duration of HM feeding varied. The source of the feeding data was referenced in 4 studies. Those with short-term follow-up generally had sufficient details to allow categorization of the amount of HM intake. Long-term follow-up studies generally relied on maternal recall, and the amount of HM intake was not quantified [31-34]. Only one study reported use of health clinic record [32] as an additional measure to minimize recall bias. No study reported the use of donor milk. Use of HM fortifier was reported in 2 studies. Preterm infant formula usage was reported in 3 studies but the type of infant formula used was not documented in the other 4 studies. In 6 of 7 studies, the control group used as a comparison with HM-fed group was from the same cohort of VLBW infants who were fed exclusively infant formula or whose daily feedings consisted of up to $80 \% \mathrm{HM}$. Only one study included children born at term and matched for sex and ethnicity and attending the same mainstream school or special education facility.

All but one study were secondary analyses of data from primary studies that may have an independent effect on neurodevelopment. The effect of HM on neurodevelopment was based on observation of selected cohorts. The quality and the risk of bias, as determined by the extent to which the methodological parameters are met, were varied among different studies (Table 5). Of the 8 non-nutritive parameters, each study has at least 4 parameters that were either not met or only partially met with the use of surrogate markers. Of the 5 nutritive parameters, one study did not meet one parameter while the other studies did not 
Table 1 Human milk (HM) and developmental outcome in very low birth weight (VLBW) infants: clinical characteristics

\begin{tabular}{|c|c|c|c|c|c|c|c|}
\hline Reference & Pinelli et al. [29] & Furman et al. [30] & Tanaka et al. [31] & Horwood et al. [32] & Smith et al. [33] & Johnson et al. [34] & Vohr et al. [35] \\
\hline Birth weight $g$ & $<1500$ & $600-1499$ & $<1500$ & $<1500$ & $<1500$ & $<1000$ & $<1000$ \\
\hline $\begin{array}{l}\text { Gestation: mean } \\
\text { (weeks, SD if available) }\end{array}$ & $\begin{array}{l}\operatorname{HM}(29,3) \text { vs. } \\
\text { Control }(29,3)\end{array}$ & All subjects $(27,2)$ & $\begin{array}{l}\operatorname{HM}(28.7,3.2) ; \\
\text { Control }(30.7,1.6) .\end{array}$ & * & $\begin{array}{l}\text { HM }(28.7,2.4) \text { vs. Control } \\
(27.8,2.5) .\end{array}$ & HM <26 vs. Control (term birth). & HM 26.7 vs. Control 26.2. \\
\hline Range of HM intake & $>80 \%$ vs. $<80 \%$ & $>50$ to $0 \mathrm{~mL} / \mathrm{kg} / \mathrm{d}$ & $>80 \%$ vs. $<80 \%$ & & $\begin{array}{l}\text { Breastfeeding at discharge } \\
\text { vs. no HM at any stage }\end{array}$ & $\begin{array}{l}\text { VLBW infants: any breast milk } \\
\text { vs. none during hospitalization. } \\
\text { Control: regardless of HM intake }\end{array}$ & $>80 \%$ vs. 0 \\
\hline$\%$ small for gestation & NS & 8 & $\begin{array}{l}\text { HM 40\%; } \\
\text { "Control" 62\% }\end{array}$ & * & NS & NS & NS \\
\hline$\%$ singleton & 100 & 100 & NS & * & 61.5 & NS & NS \\
\hline Year/s of birth & NS & Jan 1997-Feb 1999 & $1999-2000$ & 1986 & 1991-1993 & Mar-Dec 1995 & Oct 99-Jun 2001 \\
\hline
\end{tabular}

NS - not stated or specified.

*Small for gestation and multiple births entered into analysis but no raw data presented. 
Table 2 Human milk (HM) and developmental outcome in very low birth weight (VLBW) infants: non-nutritive methodological parameters

\begin{tabular}{|c|c|c|c|c|c|c|c|}
\hline Reference & Pinelli et al. [29] & Furman et al. [30] & Tanaka et al. [31] & Horwood et al. [32] & Smith et al. [33] & Johnson et al. [34] & Vohr et al. [35] \\
\hline $\begin{array}{l}\text { Primary study for } \\
\text { the subjects }\end{array}$ & $\begin{array}{l}\text { Structured breast } \\
\text { feeding counseling } \\
\text { to sustain lactation }\end{array}$ & $\begin{array}{l}\text { Self selected provision } \\
\text { of breast milk vs. preterm } \\
\text { formula }\end{array}$ & $\begin{array}{l}\text { RBC DHA in breastfed } \\
\text { VLBW infants at } 4 \text { weeks }\end{array}$ & $\begin{array}{l}\text { Retinopathy of } \\
\text { prematurity }\end{array}$ & $\begin{array}{l}\text { Epidemiology of brain } \\
\text { injuries in VLBW infants } \\
\text { and Epidemiologic } \\
\text { study of multiple births }\end{array}$ & $\begin{array}{l}\text { Early predictors of } \\
\text { education attainment } \\
\text { at } 11 \mathrm{y}\end{array}$ & $\begin{array}{l}\text { Parenteral glutamine } \\
\text { trial }\end{array}$ \\
\hline Subject source & One center, Canada & One center, USA & One center, Japan & $\begin{array}{l}\text { All VLBW births, New } \\
\text { Zealand }\end{array}$ & 5 centers, USA & $\begin{array}{l}\text { All extremely } \\
\text { preterm births in } \\
\text { United Kingdom } \\
\text { and Ireland }\end{array}$ & $\begin{array}{l}12 \text { of } 15 \text { NICHD NRN } \\
\text { sites, USA }\end{array}$ \\
\hline Exclusions & $\begin{array}{l}\text { Multiple birth, severe } \\
\text { congenital, surgical, } \\
\text { chromosome abnormality, } \\
\text { non-English speaking } \\
\text { parents }\end{array}$ & $\begin{array}{l}\text { Positive drug screen, } \\
\text { major congenital anomalies, } \\
\text { intrauterine infection, } \\
\text { overwhelming maternal } \\
\text { social concerns }\end{array}$ & $\begin{array}{l}\text { Cerebral palsy, no RBC } \\
\text { DHA data, severe chronic } \\
\text { lung disease, minor } \\
\text { anomalies, hearing } \\
\text { problem }\end{array}$ & $\begin{array}{l}\text { Sensorineural deficit } \\
\text { and no breast milk } \\
\text { data }\end{array}$ & NS & None & $\begin{array}{l}\text { Unable to test } \\
\text { including those with } \\
\text { sensorineural deficit }\end{array}$ \\
\hline Assessment age & 6 and $12 \mathrm{~m}$ corrected & $20 \mathrm{~m}$ corrected & $5 y$ & $91 \mathrm{~m}$ & 6 to $8 y$ & Median 10y $11 \mathrm{~m}$ & $30 \mathrm{~m}$ corrected \\
\hline $\begin{array}{l}\text { Sample size } \\
\text { (assessed/eligible) }^{*}\end{array}$ & $138 / 148$ & $98 / 119$ & $18 / 26$ & $298 / 338$ & $439 / 770$ & $\begin{array}{l}\text { 219/307; and } 153 \\
\text { term "Control" }\end{array}$ & $704 / 939$ \\
\hline $\begin{array}{l}\text { Observers blinded } \\
\text { to feeding protocol }\end{array}$ & Yes & Yes & NS & NS & NS & Yes & NS \\
\hline $\begin{array}{l}\text { Neurodevelopment } \\
\text { tests }\end{array}$ & BSID II: MDI and PDI & BSID II: MDI and PDI & KABC & $\begin{array}{l}\text { WISC-R: verbal and } \\
\text { performance IQ }\end{array}$ & $\begin{array}{l}\text { CELF; CCVL; KABC; } \\
\text { PPVT; WRAVMA }\end{array}$ & KABC; TAAS; WIAT-II & BSID-II \\
\hline $\begin{array}{l}\text { Effect size for } \\
\text { human milk† }\end{array}$ & See below & See below & See below & See below & See below & See below & See below \\
\hline
\end{tabular}

CI - confidence interval; NICHD NRN - National Institute of Child Health and Human Development Neonatal Research Network; NS - not stated or specified or not significant; RBC DHS red blood cell - Docosahexaenoic acid; SD - standard deviation.

Neurodevelopment tests: BSID II Bayley Scales of Infant Development (2nd edition), MDI Mental Developmental Index, PDI Psychomotor Developmental Index; CCVL California Children's Verbal Learning Test; CELF Clinical Evaluation of Language Fundamentals 3rd ed; KABC - Kaufman Assessment Battery for Children; PPVT - Peabody picture vocabulary test 3rd ed; TAAS Teachers Academic Attainment Scale; WIAT-II Wechsler Individual Achievement Test - II; WISC-R - Revised Wechsler intelligence scale for children; WRAVMA - Wide Range Assessment of Visual Motor Abilities.

*None had stated a priori power calculation to measure the neurodevelopment effect of HM. For Smith et al. [33], total sample size included 4 gestation matched VLBW controls for each VLBW subject with abnormal cranial ultrasound. For Johnson et al. [34], control subjects included one subject selected randomly from 3 classmates born at term with same sex and ethnicity.

†Effect size for human milk (maximum amount or as specified) vs none or limited human milk. Mean (SD or Cl if available) scores after adjustment for covariates and confounders:

Pinelli et al. [29]. Dichotomous groups based on 80\% HM intake as cut point: No significant difference in MDI 92 (15) vs. 91 (12) or PDI 78 (15, SD) vs. 77 (14).

Furman et al. [30]. No significant difference in MDI $85+/-21$ vs. $80+/-16$ or PDI $76+/-16$ vs. $80+/-16$.

Tanaka et al. [31]. Dichotomous groups based on 80\% HM intake as cut point: higher raw score for sequential 106.7 (14.5) vs. 94.7 (11.6) but not simultaneous or composite mental processing. No adjusted scores. Horwood et al. [32]. Higher mean verbal IQ $(102.1$ vs $96.1 \mathrm{p}<0.05)$ and performance IQ $(103.3 \mathrm{vs} .99 .6, \mathrm{p}>0.15)$ after $>8 \mathrm{~m} \mathrm{HM}$.

Smith et al. [33]. Significantly different in visual motor skills only: WRAVMA drawing 97.7 (14.6) vs, 90.6 (13.5), 95\% $\mathrm{Cl}=1.0-9.2$; and K-ABC triangle completion 10.6 (3.0) vs. 9.1 (2.5), 95\% Cl=0.1-1.7. No HM effect from Smith et al. [33]. Significantly different in visual motor skils only) WRAVMA drawing $97.7(14.6)$ vs. 90.6

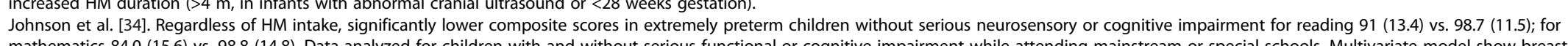
one of the independent predictors of reading scores but not mathematic scores at 11 years. Other independent predictors included BSID-II MDI, and head circumference at $30 \mathrm{~m}$, and perinatal and social factors. All independent predictors accounted for $31 \%$ of the variance for reading scores at 11 years.

Vohr et al. [35]. MDI and PDI in the highest 3 quintiles of human milk groups were higher ( $p<0.05)$ than no human milk group. Mean values for highest vs. no human milk for MDI 89.7 vs. 76.5 , and for PDI 90.2 vs 78.4. HM intake as a continuous measure show that each $10 \mathrm{~mL} / \mathrm{kg} / \mathrm{d}$ increase in human milk ingestion, the estimated increase of 0.59 points in MDI and 0.56 points in PDI. 
Table 3 Human milk (HM) and developmental outcome in very low birth weight (VLBW) infants: perinatal, postnatal, social and environmental data*

\begin{tabular}{lll}
\hline Reference & Perinatal/postnatal factors & Social and environmental factors \\
\hline Pinelli et al. [29] & Type of delivery & Maternal and paternal age, education and \\
& & occupation, 1 or 2 parent home, social \\
classes I-V (Hollingshead index) &
\end{tabular}

Furman et al. [30]

Tanaka et al. [31]

Horwood et al. [32]

Smith et al. [33]

Johnson et al. [34]

Vohr et al. [35]
Delivery at perinatal center, antenatal steroid and cesarean section. Apnea, sepsis, jaundice, necrotizing enterocolitis, chronic lung disease, cranial ultrasound abnormalities.

Chronic lung disease, cranial ultrasound, necrotizing entercolitis. Intrauterine growth retardation

Sex, multiple births, birth weight, gestational age, intrauterine growth retardation, 5 min Apgar score

Length of hospital stay
Maternal education and ethnicity, and marital status

Maternal age and education

Maternal age, education and smoking, 1 or 2 parents, family income, child ethnicity, birth order

Maternal age, verbal ability, education, cigarette smoking and marital status, Home observation for measurement of the environment inventory - short version, annual household income, gender, parity

Socioeconomic (UK National Statistics Socio-Economic classification), maternal age, race and highest education.

Maternal age and education, marital and health insurance status, race, and income.
Gestation, gender, sepsis, intraventricular hemorrhage grade 3 to 4, periventricular leukomalacia, oxygen need at 36 weeks, necrotizing enterocolitis, and weight $<10$ th percentile at 18 months.

Birth weight, gestation, antenatal steroid, premature rupture of membranes, vaginal temperature $<35^{\circ} \mathrm{C}$, CRIB score, abnormal last cranial ultrasound, necrotizing entercolitis, postnatal steroid, duration of NICU admission. Neurodevelopmental assessment results at $30 \mathrm{~m}$ and $6 \mathrm{y}$

*The variables entered into the final model to determine the independent effect of HM feeding were varied and not always fully described. Some investigators [30] used composite scores to minimize the number of variables entered into data analysis and no specific modeling was performed by other investigators [31].

meet 2 or 3 parameters (Table 5). Lack of documentation for a methodological parameter or the use of surrogate markers negatively affected the quality of many studies. Consistency of the effect is variable with the advantage of feeding HM in adjusted neurodevelopment or educational attainment test scores in 4 of the 7 reports [32-35]. Three of these studies [32-34] of VLBW children at 6 to 11 years of age showed an advantage from HM with selected subtests rather than overall test scores. Dose effect of HM intake was reported with 2 studies [32,35]. Directness of the outcome was supported with the use of age-appropriate standardized tests but suffered from secondary analysis of other studies, incomplete sampling, poor selection of control group, and use of surrogate markers.

\section{Discussion}

For infants born at term, the benefits of HM on neurodevelopment and cognitive function may be limited according to reports on studies that adequately controlled for maternal intelligence and other social and environmental factors [8-10]. HM may provide greater benefit for the preterm infants when there is an added need for specific nutrients and trophic effects. Meta-analysis of earlier studies with larger preterm infants supported this assumption [7]. However, the meta-analysis did not attempt to evaluate each study's methods or interpret results on the basis of the quality of the investigation. As a result, the pooled effect estimates obtained reflect the average of a heterogeneous group of studies.

Our systematic review on the independent effect of HM feeding on neurodevelopment outcome, taking into account the additional confounders unique to VLBW children, provided a better understanding of the strengths and limitations of each study. It appears that significant limitations exist with each study. These limitations may involve study design or the quality of the study in the fulfillment of non-nutritional and nutritional methodological criteria, which can affect the applicability of the outcome data. The inconsistent effect on neurodevelopment test scores and variable advantage in different subtest scores when assessed at school ages also contributed to the difficulty in interpreting the HM effect on neurodevelopment outcome. 


\section{Table 4 Human milk (HM) and developmental outcome in very low birth weight (VLBW) infants: nutritive parameters}

\begin{tabular}{|c|c|c|c|c|c|c|c|}
\hline Reference & Pinelli et al. [29] & Furman et al. [30] & Tanaka et al. [31] & Horwood et al. [32] & Smith et al. [33] & Johnson et al. [34] & Vohr et al. [35] \\
\hline $\begin{array}{l}\text { HM feeding definition. } \\
\text { None specified whether } \\
\text { donor milk was used. }\end{array}$ & $\begin{array}{l}\text { Maternal milk intake as } \\
\% \text { of total fluid intake and } \\
\text { by duration }\end{array}$ & $\begin{array}{l}\text { Maternal milk at 0, 1-24, } \\
25-49,>50 \mathrm{~mL} / \mathrm{kg} / \mathrm{d}\end{array}$ & Maternal milk & $\begin{array}{l}\text { Any maternal milk } \\
\text { from birth }\end{array}$ & $\begin{array}{l}\text { Expressed maternal } \\
\text { milk without or with } \\
\text { progression to direct } \\
\text { breastfeeding }\end{array}$ & Any breast milk & $\begin{array}{l}\text { Maternal milk } \\
\text { intake by quintiles }\end{array}$ \\
\hline HM feeding duration & $\begin{array}{l}\text { Continuous measures till } \\
12 \mathrm{~m} \text { corrected }\end{array}$ & Up to $4 w$ & $\begin{array}{l}\text { HM group } 72+/ \\
-45.2 \text { (SD)d, Formula } \\
\text { group received HM for } \\
59+/-32.1 \mathrm{~d}\end{array}$ & $\begin{array}{l}\text { None, }<4 \mathrm{~m}, 4-7 \mathrm{~m}, \\
8+\mathrm{m}\end{array}$ & $\begin{array}{l}<1 \mathrm{w}, 1-4 \mathrm{w}, 1-3 \mathrm{~m}, 4-6 \\
\mathrm{~m},>6 \mathrm{~m}\end{array}$ & Neonatal period & Up to $120 \mathrm{~d}$. \\
\hline HM fortification & $\begin{array}{l}\text { Milk based powder if intake } \\
<180-200 \mathrm{~mL} / \mathrm{kg} / \mathrm{d} \\
\text { ( } 21 \% \text { of infants) }\end{array}$ & $\begin{array}{l}\text { Milk based powder or } \\
\text { concentrated PTF }\end{array}$ & NS & NS & NS & NS & NS \\
\hline $\begin{array}{l}\text { HM feeding data } \\
\text { source }\end{array}$ & $\begin{array}{l}\text { Maternal questionnaires, } \\
24 \mathrm{~h} \text { expressed milk volume, } \\
\text { test weighing one feeding } \\
\text { each } 3 \mathrm{~m}\end{array}$ & $*$ & * & $\begin{array}{l}\text { Maternal recall and } \\
\text { child health record }\end{array}$ & Maternal recall & * & $\begin{array}{l}\text { Database from } \\
\text { hospital records }\end{array}$ \\
\hline Infant formula data & 20 exclusively PTF & PTF & NS & $N S, n=76$ & NS & NS & $\begin{array}{l}\text { PTF, } 180(23 \%) \\
\text { exclusively FF }\end{array}$ \\
\hline
\end{tabular}

PTF - Preterm formula in hospital, FF - formula fed, NS - not stated or specified.

*Not stated and presumably were obtained from review of hospital record. 
Table 5 Studies of human milk (HM) feeding and developmental outcome in very low birth weight (VLBW) infants: meeting criteria for methodological quality \begin{tabular}{lllllll}
\hline Reference & Pinelli et al. [29] & Furman et al. [30] & Tanaka et al. [31] & Horwood et al. [32] & Smith et al. [33] Johnson et al. [34] Vohr et al. [35] \\
\hline
\end{tabular}

As primary outcome of original study* Pinelli et al. [29] $\quad$ Furn

VLBW only

$+\quad+$

$+$

$-$

A priori power calculation

Baseline adjustment for SGA

Postnatal complication

Maternal intelligence

-
-
-

Social class or Socioeconomic status

Child rearing environment

$+/-\quad+/$

$+$

$+$

$+$

$+十$

$+1-$

Observers blinded to feeding protocol

Effect size after adjustment

Human milk definition

Human milk duration

Human milk fortification

Human milk feeding data source

Formula type

$+1-+$

+/

$+$

$+$

$+/-$

$+$

SGA = Small for gestational age, $\mathrm{NA}=$ not available

+Met methodological criterion.

-Did not meet methodological criterion; or not stated or not specified in the publication.

+/-Use surrogates such as income for socioeconomic status, maternal education for maternal intelligence, marital status or one or two parent family for child rearing environment.

*All studies were observational and most were secondary analysis of study cohort from other studies.

tOnly children with birth weights $<1000 \mathrm{~g}$.

${ }^{\ddagger}$ Limited consistency of neurodevelopment outcome. Human milk showed variable advantage in some test scores [32-35]. 
Majority of publications determining the effect of breast milk feeding on neurodevelopment in VLBW children is based on observational data from other studies. The source of VLBW population for example those with postnatal complications [32,33]; and intervention performed in the original studies, such as counseling to improve breastfeeding [29] or glutamine supplementation in parenteral nutrition [35] potentially may influence the outcome measures by indirect means. Furthermore, secondary analysis of data generates more questions for hypothesis testing rather than providing a definitive cause and effect of HM feeding.

Quality of the studies, as indicated by adherence to methodological criteria that minimizes risks for bias, is generally low. Numerous factors other than nutritional intake have been identified as confounding variables in relation to child development [40] and may have origin even before birth. Many preterm infants experienced variable adverse growth in utero but not all studies reported the rate of IUGR or SGA. In preterm infants, SGA is an independent predictor of severe cognitive deficit [17]. For extremely preterm infants with VLBW, SGA as an indicator of IUGR has an odds ratio of 3.91 for increased risk of death or neurodevelopment impairment [41]. Some studies of children born preterm have reported IUGR or SGA rates from 34\% [26] to as high as $60 \%$ [31], and not all studies reported whether or how the data analysis accounted for IUGR or SGA. Extra uterine growth retardation also occurs frequently in VLBW infants and may be another marker for neurodevelopment delay [42]. A small head circumference at 8 months corrected age is an independent marker of neurodevelopment and cognitive impairment, independent of the type of feeding $[43,44]$. Multiple births are at risk for preterm delivery and discrepant in utero growth resulting in VLBW and IUGR, and discordant neurodevelopment outcome has been reported for VLBW twins [45]. Not all studies have accounted for multiple births and some studies have restricted the study population to singletons $[29,30]$. In addition, the effect on breast milk production in mothers with both twins admitted to a neonatal intensive care unit is not well-defined.

For extremely preterm infants, a difference in $100 \mathrm{~g}$ in birth weight or one week of gestation can have major impact on perinatal and postnatal complications [46] that can directly or indirectly impact neurodevelopment outcome and confound the effects of HM. Thus it is important not to generalize the neurodevelopment effect of HM from preterm infants with higher birth weight and gestation, since they have a relatively longer period of development in utero and less serious postnatal complications. The earlier reports included large numbers of preterm children with higher birth weights than VLBW which could reflect better intrauterine growth at the same gestation or had IUGR at a more advanced gestation [11,17-28]. Interaction between gender and diet has been reported in some studies, with males showing more benefit from nutritional intervention [11,26,34]. One study of children with birth weight $<1000 \mathrm{~g}$ reported that being male has a small negative predictive effect on reading but not mathematics attainment at 11 years [34].

The age at follow-up varies, although few studies [32-34] assessed cognitive scores at school ages which are considered as much better predictors of adult scores. One report of significant positive effect of HM on neurodevelopment at 30 months corrected age was generated from secondary analysis of a subpopulation from another project [35]. In the same cohort, there was a significant increase in MDI scores by 2.7 points in the HM group and a trend to lower PDI scores by 2.3 points in the non-HM group since an earlier assessment at 18 months [36]. This drift in test scores could bias the outcome that showed HM group has higher MDI and PDI scores at 30 months [35]. The advantage associated with HM feeding appears to diminish with older children, as the improvement in test scores is limited to selected and different subtests [32-34]. It is possible that the effect of HM may be less important as genetic and environmental factors play bigger roles at school age. In some cohorts with follow up at older ages, the validity of mother's milk effect on IQ at adolescence is questionable since the data is based on $<10 \%$ of the subjects from the original cohort [22].

Age-appropriate developmental or cognitive tests standardized to normal age matched children allow the use of a control group from the same VLBW cohort [29-33,35]. Only one study used selected classmates in the same educational setting and born at term with same sex and ethnicity and tested during the same period to minimize any secular drift in test scores over time [34]. Selection of a control group based on the volume of human milk ingested heavily influences the outcome. Any HM effect on neurodevelopment may be difficult to detect when the data analysis is dichotomized using a large volume of HM consumption as a cutoff point $[29,31]$. Not all reports indicated whether the testers were blind to feeding status thus contributing to the risk for bias.

The extensive numbers of potential confounders of neurodevelopment and variable exclusion criteria based on the type and extent of postnatal complications support the need for appropriate statistical modeling and large sample size to provide meaningful interpretation of the neurodevelopment effect of feeding HM. One study employed a composite neonatal risk score and a composite socioeconomic score to minimize the number of independent variables and to avoid multi-colinearity of variables in statistical modeling [30]. However, there is 
no uniform approach to statistical modeling and none of the studies had stated a priori power calculation to measure the neurodevelopment effect of HM.

Both breastfeeding and neurodevelopment outcome are confounded by maternal intelligence, social and socioeconomic status, and child rearing environment, and possibly from intangible psychobiology of maternal behavior and mother-infant relationship $[10,47,48]$. Mothers elected to provide HM and breastfeeding are often highly motivated and possibly more health conscious and more likely to stimulate their infants thus contributing to self-selection bias. None of the studies reviewed have formal assessment of maternal intelligence and few studies specifically assessed the other confounders. The use of surrogate for these critical independent determinants of neurodevelopment outcome limits the validity of HM effect.

It is important to recognize that VLBW children with no neurological impairment and fed HM achieved normal or low normal scores on standardized tests of neurodevelopment or cognitive function. The VLBW children fed a lower amount of HM or fed infant formula have lower test scores. One should consider feeding HM as protective rather than providing an added advantage to neurodevelopment.

Nutritive factors are important in the evaluation of the role of HM in neurodevelopment and cognitive function of VLBW children. In a cohort of children born preterm and including those with VLBW enrolled in a quasirandomized study of supplementing OMM with DM or infant formulas, preliminary data at 7.5 to 8 years from the first 300 children out of 926 subjects showed that the children who received OMM had IQ scores in the normal range. However, those who exclusively received formula have overall test scores that were 8.3 points lower [11]. In a subsequent report of 377 subjects from several subsets in the same cohort of infants, those who received infant formula (nutrient enriched versus regular formula), and either exclusively or as a supplement to OMM, experienced a beneficial effect to neurodevelopment that appeared primarily to be related to the use of the nutrient enriched formula [26]. Unfortunately, no quantifiable data specific to VLBW children was presented in either report.

In the studies reviewed, the contents of nutrients in infant formulas and HM fortifiers are in much lower quantity and lack additional nutrients such as LCPUFA when compared to the current formulations. If better nutrient profile is critical to neurodevelopment, then it is possible that all VLBW infants could benefit with the use of newer and better fortified formulas and HM fortifiers.

The timing, volume and duration of HM consumed could be important for neurodevelopment. Significant advantage in neurodevelopment effect appears to occur even after a brief period of consumption of OMM during initial hospitalization as $>88 \%$ of infants in one study [11] and $77 \%$ of infants in another study [35] received no HM by the time of hospital discharge. Unfortunately, these details are extremely limited in long-term follow-up studies.

A dose effect of OMM also may be present. Preterm infants whose mothers intended to breastfeed but could not provide any breast milk, performed at the level of exclusively formula fed children on cognitive testing at 7.5 to 8 years [11], and a dose effect was also demonstrated when the analysis was performed with HM intake as a continuum [35]. One long-term VLBW population cohort at 7 to 8 years of age showed a significant benefit of prolonged breastfeeding and reached a mean of 6 points advantage in verbal IQ after receiving OMM for 8 months or more [32]. However, no additional benefit beyond 4 months of breastfeeding was reported in another study of VLBW children at 6 years [33]. A modest independent beneficial effect of feeding OMM during the neonatal period on higher reading but not mathematics attainment at 11 years was also reported [34].

It is important to determine whether OMM or DM was used in the assessment of HM's effect on neurodevelopment. Fresh OMM contains many components that may provide trophic actions which can directly or indirectly influence the growth and development of the nervous system but are inactivated or destroyed during processing of the DM $[6,49]$. The use of DM alone or as supplement to OMM resulted in poorer growth and neurodevelopment [23]. It appears that VLBW children in all studies reviewed were provided with OMM; none reported that any DM was used. The use of HM fortifiers was reported in two studies [29,30]. In another study, the use of human milk fortifier was not specified but was likely provided since the cohorts were born in the era when HM fortification was the standard of care [35].

It is possible that space limitation imposed by the journals may have precluded detail description by the investigators, although it is unlikely to eliminate all significant limitations that exist with each study. Limitations to our study included at least the following: we evaluated original peer reviewed studies only in English and did not pursue details from published abstracts or the authors. However, abstracts have not undergone the same rigor in review process as the full publication and are unlikely to have sufficient data to allow meaningful systematic review of the data. Information from the authors is unlikely to resolve the many methodological concerns in the studies reviewed, and additional information would be unlikely to alter the overall conclusions. Our study also excluded 13 reports [11,17-28] because of insufficient data to delineate the effect of HM feeding on 
neurodevelopment outcome in children with VLBW. The data from these reports included many children with higher birth weights and thus at lower risk of neurodevelopment deficit than VLBW children. Furthermore, reports based on subsets of original cohort make it difficult to interpret the significance of the finding in the context of the whole population and should be considered as hypothesis generating rather than definitive data on the neurodevelopment benefit of HM.

In addition, the two population observational studies $[17,28]$ were confounded by the HM fed cohorts having significantly greater birth weights and gestations compared to non HM group. In any case, the neurodevelopment scores in those fed predominantly OMM [11,17-28] are generally within the normal ranges and consistent with reports that include only children with VLBW [29-35].

\section{Conclusions}

There is no randomized clinical trial comparing the neurodevelopment outcome of $\mathrm{HM}$ versus formula or minimal HM feeding that included only children with VLBW. Studies to date have significant methodological limitations although limited data suggest a possible protective effect on neurodevelopment from feeding OMM for a short period after birth and a possible dose effect on the volume and duration of feeding OMM. If better overall nutrient profile is more important for optimal neurodevelopment, it is theoretically possible that the use of current formulations of HM fortifier and preterm infant formulas could improve the neurodevelopment outcome of all VLBW children. Thus, the role of maternal milk in neurodevelopment and cognitive function of VLBW infants needs to be reassessed with high quality studies in the context of current formulations of HM fortifier and preterm formula. With increasing use of DM to the exclusion of preterm formula in NICU, a separate assessment of the role of DM in neurodevelopment is needed in view of the numerous differences between OMM and DM.

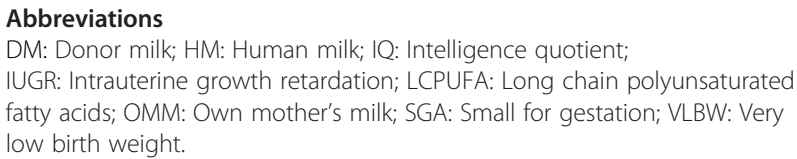

Abbreviations

DM: Donor milk; HM: Human milk; IQ: Intelligence quotient: IUGR: Intrauterine growth retardation; LCPUFA: Long chain polyunsaturated fatty acids; OMM: Own mother's milk; SGA: Small for gestation; VLBW: Very low birth weight.

\section{Competing interests}

The authors declare that they have no competing interests.

\section{Authors' contributions}

WK conceptualized and designed the study, contributed to data acquisition and interpretation, and drafted the initial manuscript. ST and SM contributed to study design, data acquisition and interpretation, and review of manuscript. SM was also responsible for the literature search. RS contributed to study design, data interpretation, and review of manuscript. All authors read and approved the final manuscript.

\section{Acknowledgements}

The authors thank Alicia LaDuke, BS, MLIS, for assistance in the initial literature search; and Lawrence Ku, MD and Monica Salari BS, for assistance in the preliminary screening and review of the publications.

\section{Author details}

${ }^{1}$ Department of Pediatrics, Louisiana State University Health Sciences, 1501 Kings Hwy, Shreveport, LA, USA. ²Shiffman Medical Library, 320 E. Canfield, Detroit, MI, USA. ${ }^{3}$ Department of Medicine \& Feist-Weiller Cancer Center, Louisiana State University Health Sciences, 1501 Kings Hwy, Shreveport, LA, USA.

Received: 5 May 2014 Accepted: 15 September 2014

Published: 18 September 2014

\section{References}

1. Hack M, Klein N: Young adult attainments of preterm infants. JAMA 2006, 295(6):695-696.

2. Horbar JD, Carpenter JH, Badger GJ, Kenny MJ, Soll RF, Morrow KA, Buzas JS: Mortality and neonatal morbidity among infants 501 to 1500 grams from 2000 to 2009. Pediatrics 2012, 129:1019-1026.

3. Litt JS, Gerry Taylor H, Margevicius S, Schluchter M, Andreias L, Hack M: Academic achievement of adolescents born with extremely low birth weight. Acta Paediatr 2012, 101(12):1240-1245.

4. ESPGHAN Committee on Nutrition: Enteral nutrient supply for preterm infants. A comment of the ESPGHAN Committee on Nutrition 2009. http://links.Iww. com/A1480. Accessed Feb 4, 2014.

5. American Academy of Pediatrics: Policy statement. Breastfeeding and the use of human milk: section on breastfeeding. Pediatrics 2012, 129:e827-e841.

6. Nutritional Needs of the Preterm Infant. In Pediatric Nutrition. 7th edition. Edited by Kleinman RE, Greer F. Elk Grove Village, IL: American Academy of Pediatrics; 2013:83-121.

7. Anderson JW, Johnstone BM, Remley DT: Breast-feeding and cognitive development: a meta-analysis. Am J Clin Nutr 1999, 70:525-535.

8. Jacobson SW, Chiodo LM, Jacobson JL: Breastfeeding effects on intelligence quotient in 4- and 11-year-old children. Pediatrics 1999, 103(5):e71.

9. Jain A, Concato J, Leventhal JM: How good is the evidence linking breastfeeding and intelligence? Pediatrics 2002, 109:1044-1053.

10. Der G, Batty GD, Deary IJ: Effects of breast feeding on intelligence in children: prospective study, sibling pairs analysis, and meta-analysis. BMJ 2006, 333(7575):945.

11. Lucas A, Morley R, Cole TJ, Lister G, Leeson-Payne C: Breast milk and subsequent intelligence quotient in children born preterm. Lancet 1992, 339(8788):261-264.

12. Moher D: Preferred reporting items for systematic reviews and meta-analyses: the PRISMA statement. BMJ 2009, 339:b2535.

13. Bauchner $H$, Leventhal JM, Shapiro ED: Studies of breast feeding and infections. How good is the evidence? JAMA 1986, 256:887-892.

14. Silva PA: Experiences, activities, and the preschool child: a report from the Dunedin multidisciplinary child study. Aust J Early Child 1980, 5:13-19.

15. Caldwell BM, Bradley RH: Home Observation for the Measurement of the Environment. Little Rock, AR: University of Arkansas; 1984.

16. Atkins D, Best D, Briss PA, Eccles $M$, Falck-Ytter $Y$, Flottorp $S$, Guyatt $G H$, Harbour RT, Haugh MC, Henry D, Hill S, Jaeschke R, Leng G, Liberati A, Magrini N, Mason J, Middleton P, Mrukowicz J, O'Connell D, Oxman AD, Phillips B, Schünemann HJ, Edejer T, Varonen H, Vist G, Williams JW Jr, Zaza S: Grading quality of evidence and strength of recommendations. BMJ 2004, 328(7454):1490-1494.

17. Beaino G, Khoshnood B, Kaminski M, Marret S, Pierrat V, Vieux R, Thiriez G, Matis J, Picaud J, Rozé J, Alberge C, Larroque B, Bréart G, Ancel P: Predictors of the risk of cognitive deficiency in very preterm infants: the EPIPAGE prospective cohort. Acta Paediatrica 2011, 100(3):370-378.

18. Bier JA, Oliver T, Ferguson AE, Vohr BR: Human milk improves cognitive and motor development of premature infants during infancy. $J$ Hum Lact 2002, 18(4):361-367.

19. Eidelman Al, Feldman R: Positive effect of human milk on neurobehavioral and cognitive development of premature infants. Adv Exp Med Biol 2004, 554:359-364. 
20. Elgen I, Sommerfelt $K$, Ellertsen B: Cognitive performance in a low birth weight cohort at 5 and 11 years of age. Pediatr Neurol 2003, 29(2):111-116

21. Feldman R, Eidelman Al: Direct and indirect effects of breast milk on the neurobehavioral and cognitive development of premature infants. Dev Psychobiol 2003, 43(2):109-119.

22. Isaacs EB, Fischl BR, Quinn BT, Chong WK, Gadian DG, Lucas A: Impact of breast milk on intelligence quotient, brain size, and white matter development. Pediatr Res 2010, 67(4):357-362.

23. Lucas A, Morley R, Cole TJ, Gore SM, Davis JA, Bamford MF Dossetor JF: Early diet in preterm babies and developmental status in infancy. Arch Dis Child 1989, 64(11):1570-1578.

24. Lucas A, Morley R, Cole TJ, Gore SM, Jucas PJ, Crowle P, Pearse R, Boon AJ, Powell R: Early diet in preterm babies and developmental status at 18 months. Lancet 1990, 335(8704):1477-1481.

25. Lucas A, Morley R, Cole TJ, Gore SM: A randomised multicentre study of human milk versus formula and later development in preterm infants. Arch Dis Child Fetal Neonatal Ed 1994, 70(2):F141-F146.

26. Lucas A, Morley R, Cole TJ: Randomised trial of early diet in preterm babies and later intelligence quotient. BMJ 1998, 317(7171):1481-1487.

27. O'Connor DL, Jacobs J, Hall R, Adamkin D, Auestad N, Castillo M, Connor W, Connor S, Fitzgerald K, Groh-Wargo S, Hartmann E, Janowsky J, Lucas A, Margeson D, Mena P, Neuringer M, Ross G, Singer L, Stephenson T, Szabo J, Zemon V: Growth and development of premature infants fed predominantly human milk, predominantly premature infant formula, or a combination of human milk and premature formula. J Pediatr Gastroenterol Nutr 2003, 37(4):437-446.

28. Rozé JC, Darmaun D, Boquien CY, Flamant C, Picaud JC, Savagner C, Claris O, Lapillonne A, Mitanchez D, Branger B, Simeoni U, Kaminski M, Ancel PY: The apparent breastfeeding paradox in very preterm infants: relationship between breast feeding, early weight gain and neurodevelopment based on results from two cohorts, EPIPAGE and LIFT. BMJ Open 2012, 2:e000834.

29. Pinelli J, Saigal S, Atkinson SA: Effect of breastmilk consumption on neurodevelopmental outcomes at 6 and 12 months of age in VLBW infants. Adv Neonat Care 2003, 3(2):76-87.

30. Furman L, Wilson-Costello D, Friedman H, Taylor HG, Minich N, Hack M: The effect of neonatal maternal milk feeding on the neurodevelopmental outcome of very low birth weight infants. J Dev Behav Pediatr 2004, 25(4):247-253

31. Tanaka K, Kon N, Ohkawa N, Yoshikawa N, Shimizu T: Does breastfeeding in the neonatal period influence the cognitive function of very-lowbirth-weight infants at 5 years of age? Brain Dev 2009, 31(4):288-293.

32. Horwood LJ, Darlow BA, Mogridge N: Breast milk feeding and cognitive ability at 7-8 years. Arch Dis Child Fetal Neonatal Ed 2001, 84(1):F23-F27.

33. Smith MM, Durkin M, Hinton VJ, Bellinger D, Kuhn L: Influence of breastfeeding on cognitive outcomes at age 6-8 years: follow-up of very low birth weight infants. Am J Epidemio/ 2003, 158(11):1075-1082.

34. Johnson S, Wolke D, Hennessy E, Marlow N: Educational outcomes in extremely preterm children: neuropsychological correlates and predictors of attainment. Dev Neuropsychol 2011, 36(1):74-95.

35. Vohr BR, Poindexter BB, Dusick AM, McKinley LT, Higgins RD, Langer JC, Poole WK, NICHD neonatal research network: Persistent beneficial effects of breast milk ingested in the neonatal intensive care unit on outcomes of extremely low birth weight infants at 30 months of age. Pediatrics 2007, 120(4):e953-e959.

36. Vohr BR, Poindexter BB, Dusick AM, MCKinley LT, Wright LL, Langer JC, Poole WK: NICHD neonatal research network: beneficial effects of breast milk in the neonatal intensive care unit on the developmental outcome of extremely low birth weight infants at 18 months of age. Pediatrics 2006, 118(1):e115-e123.

37. Were FN, Bwibo N: Neonatal nutrition and later outcomes of very low birth weight infants at Kenyatta national hospital. Afr Hlth Sci 2007, 7:108-114.

38. Henriksen C, Haugholt K, Lindgren M, Aurvåg AK, Rønnestad A, Grønn M, Solberg R, Moen A, Nakstad B, Berge RK, Smith L, Iversen PO, Drevon CA: Improved cognitive development among preterm infants attributable to early supplementation of human milk with docosahexaenoic acid and arachidonic acid. Pediatrics 2008, 121(6):1137-1145.

39. Westerberg AC, Schei $R$, Henriksen C, Smith L, Veierød MB, Drevon CA Iversen PO: Attention among very low birth weight infants following early supplementation with docosahexaenoic and arachidonic acid. Acta Paediatr 2011, 100(1):47-52.

40. Singer LT: Randomized clinical trials in infancy: methodologic issues. Semin Neonatol 2001, 6(5):112-117.

41. De Jesus LC, Pappas A, Shankaran S, Li L, Das A, Bell EF, Stoll B, Laptook AR Walsh MC, Hale EC, Newman NS, Bara R, Higgins RD: Outcomes of small for gestational age infants born at $<27$ weeks' gestation. J Pediatr 2013, 163(1):55-60.e1-3.

42. Ehrenkranz RA: Extrauterine growth restriction: is it preventable? J Pediatr (Rio J) 2014, 90(1):1-3.

43. Hack M, Breslau N, Fanaroff AA: Differential effects of intrauterine and postnatal brain growth failure in infants of very low birth weight. Am J Dis Child 1989, 143(1):63-68.

44. Hack M, Breslau N, Weissman B, Aram D, Klein N, Borawski E: Effect of very low birth weight and subnormal head size on cognitive abilities at school age. N Engl J Med 1991, 325(4):231-237.

45. Steingass KJ, Taylor HG, Wilson-Costello D, Minich N, Hack M: Discordance in neonatal risk factors and early childhood outcomes of very low birth weight $(<1.5 \mathrm{~kg})$ twins. J Perinato/ 2013, 33(5):388-393.

46. NICHD Neonatal Research Network (NRN): Extremely Preterm Birth Outcome Data. http://www.nichd.nih.gov/about/org/der/branches/ppb/programs/ epbo/Pages/index.aspx. Accessed Feb 16, 2014.

47. Lucas A, Cole TJ, Morley R, Lucas PJ, Davis JA, Bamford MF, Crowle P, Dossetor JF, Pearse R, Boon A: Factors associated with maternal choice to provide breast milk for low birthweight infants. Arch Dis Child 1988, 63(1):48-52.

48. Long Term Effects of Breastfeeding: a Systematic Review. World Health Organization; 2013:57-67. http://apps.who.int/iris/bitstream/10665/79198/1/ 9789241505307_eng.pdf?ua=1. Accessed May 4, 2014.

49. Composition of Human Milk. In Breastfeeding Handbook for Physicians. 2nd edition. Edited by Schanler RJ, Krebs NF, Mass SB. Elk Grove Village, IL: American Academy of Pediatrics; 2014:41-51.

doi:10.1186/1475-2891-13-94

Cite this article as: Koo et al:: Human milk and neurodevelopment in children with very low birth weight: a systematic review. Nutrition Journal 2014 13:94.

\section{Submit your next manuscript to BioMed Central and take full advantage of:}

- Convenient online submission

- Thorough peer review

- No space constraints or color figure charges

- Immediate publication on acceptance

- Inclusion in PubMed, CAS, Scopus and Google Scholar

- Research which is freely available for redistribution 